\title{
Hydrologic modeling support for sustainable water resources management
}

\author{
R. G. Quimpo \\ University of Pittsburgh, Pittsburgh, PA, USA
}

\begin{abstract}
Prior to the implementation of an infrastructure project, an environmental impact assessment is necessary to secure the acceptance of stakeholders and the approval of various regulating agencies. Since the project has not yet been constructed, the projected impacts are based on surveys and modeling studies that need to be verified during and after construction. In projects which impact the water resources of a region, planners and designers use hydrologic models to predict future conditions on water quantity and quality. This paper will focus on the hydrologic modeling, instrumentation and monitoring requirements using as case study the design and construction of a stretch of the Interstate system of highways in the United States.

The highway segment traverses agricultural, forest and game lands resulting in the alteration of landscapes and changes in watershed delineations. In some sections of the project, the highway cross-section includes an infiltration gallery constructed under the roadway which permits groundwater flow from headwater areas to bypass the construction corridor. The behavior of the altered watersheds needs to be examined to determine if they conform reasonably with projected performance. Aspects of the study related to runoff modeling and prediction, storm water sediment and erosion practices, wetland and stream restoration were investigated. The logistics of instrumentation, monitoring, data-acquisition and analyses are discussed. The findings will form the basis for developing guidelines for use by the implementing agency in future projects.
\end{abstract}

Keywords: hydrologic models, hydrologic monitoring, erosion and sedimentation, environmental impact, infiltration gallery, stream restoration, watersheds, wetlands, BMP, watersheds. 


\section{Introduction}

In the last quarter century, the tenet of environmental responsibility has been embraced almost universally. Even less developed countries whose primary concern is the improvement of the population's standard of living have implemented programs to protect the environment. In countries with proactive population, non-governmental groups exert political pressure on government institutions to focus attention on potential risks to the environment when economic development projects are proposed. As a result, regulatory agencies have been set up to monitor the planning, design and implementation of projects.

Formally, environmental impact assessment (EIA) is a planning tool that is now regarded as an integral component of sound decision making. Its purposes include the support of the goals of environmental protection and sustainable development; the integration of environmental protection and economic decisions and the assessment of plans to mitigate any adverse impacts; and providing for the involvement of the public and government agencies in the review of proposed activities in the project. In the United States, EIA is pervasive and has filtered down from the federal and state to municipal levels of government.

To mitigate the conflict between projected economic benefits and adverse environmental impacts, the concept of sustainability has evolved. The Bruntland Report [1] defines sustainable development as that which "meets the needs of the present generation without compromising the ability of future generations to meet their own needs." This definition implies limitations imposed by the state of technology and social organization on the environment ability to meet present and future needs.

\section{Need for modeling support - a case study}

In assessing water quality, the assessment tools require that hydrologic variables be quantified. While general hydrologic models are useful for the qualitative analysis of overall project impacts, if it is desired to investigate specific mitigation strategies, it is necessary to develop a site-specific model of hydrologic interactions that result from the project. This paper examines the needs for quantitative hydrologic modeling and how they were addressed in assessing the environmental impact of highway construction. The case study derives from the use of new technology in the design and construction of a segment of Interstate-99 in Pennsylvania in the United States. The project was enabled by federal legislation and is intended to improve the transport capacity of the existing highway routes and facilitate product mobility in the region. The route of the highway passes through headwater regions of forests and farms and straddles protected game lands. The construction project is managed by the Pennsylvania Department of Transportation (PennDOT).

The highway was designed with the assistance of consulting engineers following design guidelines developed by PennDOT. In addition to the consultants, PennDOT has a complement of planners, engineers, 
environmentalists and social scientists who as a matter of policy use the available technology in all the projects that the agency undertakes, subject to cost and environmental constraints. Environmental protection legislation regulates many of the planning procedures. State and federal agencies have developed guidelines regarding the design of highways and their appurtenant structures in order to minimize the impacts of such projects.

Pursuant to EIA guidelines, PennDOT sought the opinion and advice of all the stakeholders. To keep all stakeholders fully informed, a policy of strict transparency was adopted to dispel any fears and apprehensions that constituencies typically experience whenever changes in their environment are proposed. Often conflicts arise between the designers and the constructors on one side and regulating agencies, who are often supported by public interest groups and local community movements, on the other side.

The design of the highway incorporated many technologies that the designers believe will improve the project's effectiveness in minimizing adverse environmental impacts. In the design and construction, both source and treatment Best Management Practices (BMPs) for erosion and sedimentation control were adopted. These include installation of silt fences during construction, detention and sedimentation ponds to capture sediment and runoff from the construction site, wetland mitigation and stream restoration activities. Also included is a new feature in the design of the highway cross-section - the incorporation of an infiltration gallery constructed underneath the roadway. The gallery was designed to direct groundwater from upstream of the highway to the area downstream and bypassing the area that is disturbed by construction.

Plans for the project went through federal and state regulatory scrutiny. Public hearings and town meetings were conducted to provide opportunities for the public and all stakeholders to voice their concerns. Although no specific objections to the design were raised, a consensus on the overall impacts of the project on the receiving waters and wetlands downstream was difficult to achieve. Eventually, a compromise was arranged to resolve the remaining issues. PennDOT agreed to have an independent group conduct a verification of the effectiveness of the technology used in the design. PennDOT contracted with the University of Pittsburgh to carry out a testing and monitoring program to investigate the environmental impact of the project.

In examining the effectiveness of the design, hydrologic modeling support is necessary. We will focus on two technologies. These are the use of detention and sedimentation ponds and the incorporation of the infiltration gallery constructed underneath the roadway.

\section{Hydrologic setting}

The drainage of hill slopes is characterized by small gullies and creeks which run downstream from the ridge to the valley floor. The gullies generally have steep slopes and would drain relatively narrow strips of area until the gullies reach a flatter topography when they combine to form creeks which become tributaries 
of the main drainage channel. The main channel would run almost parallel the ridge line in the direction of the downstream gradient. A highway, which runs parallel to the ridge, would intercept the steep-sloped channels and form creeks which drain at the bottom of the valley approximately parallel to the ridge line along a downstream gradient.

In this setting highway construction significantly alters the watershed. As a result of the project, many small watersheds were subtended by the highway. These small watersheds would cover only several tens or a few hundred acres. Since there would be many of these sub-watersheds throughout the length of the construction project, only two watersheds were investigated. The locations of the two test watersheds are shown in Figure 1. Figure 2 shows a schematic representation of Watershed 1 in greater detail. For the purpose of modeling, the watershed consists of seven subareas; a clean watershed upstream of the highway which channels runoff under the roadway to the outlet; five sub-watersheds representing the pavement and another sub-watershed downslope of the roadway. Except for the first sub-watershed, the other six watersheds carry dirty water. The roadway sub-catchments and the dirty sub-watershed drain into two sedimentation ponds. The pond outlets then discharge into a channel to join the clean water from the upstream sub-watershed and the accumulated flows are transported to the watershed outlet.

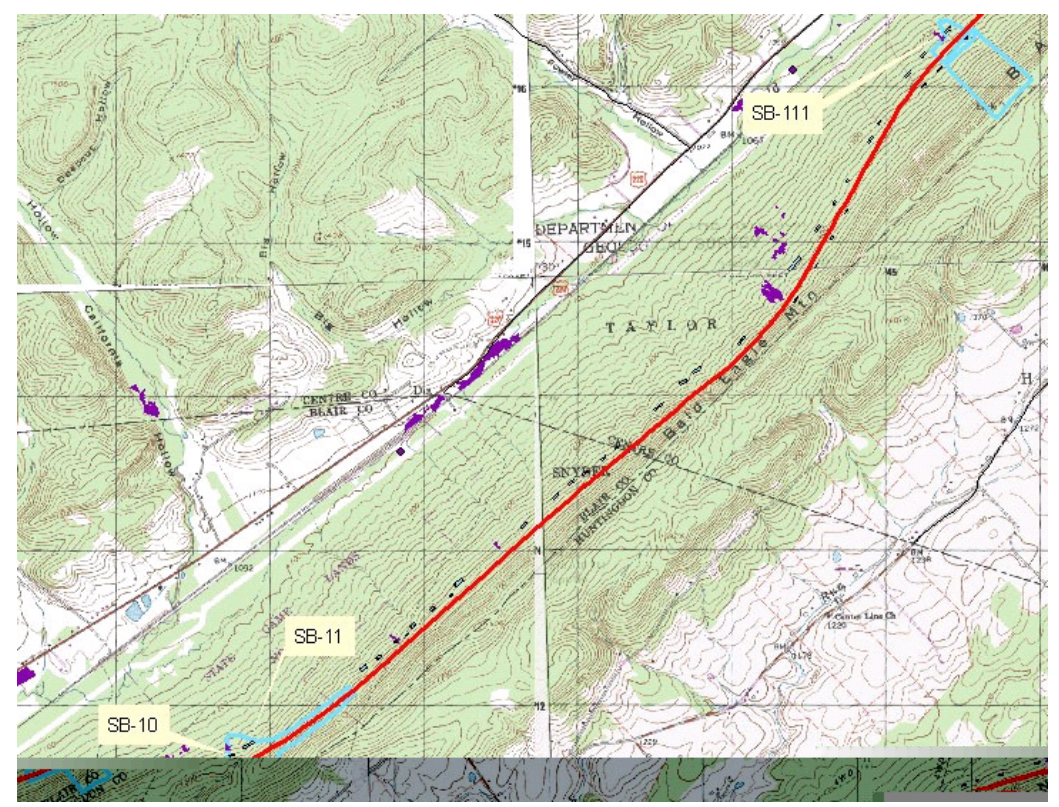

Figure 1: Location of construction relative to receiving stream. 


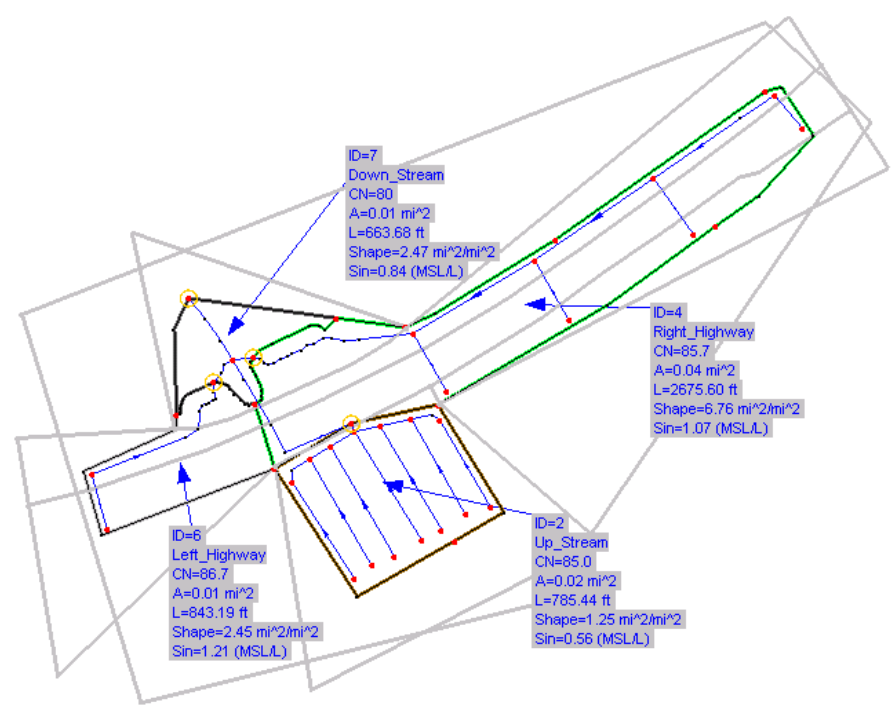

Figure 2: $\quad$ Schematic of watershed model.

\section{Station 183.50: SB10 and SB11}

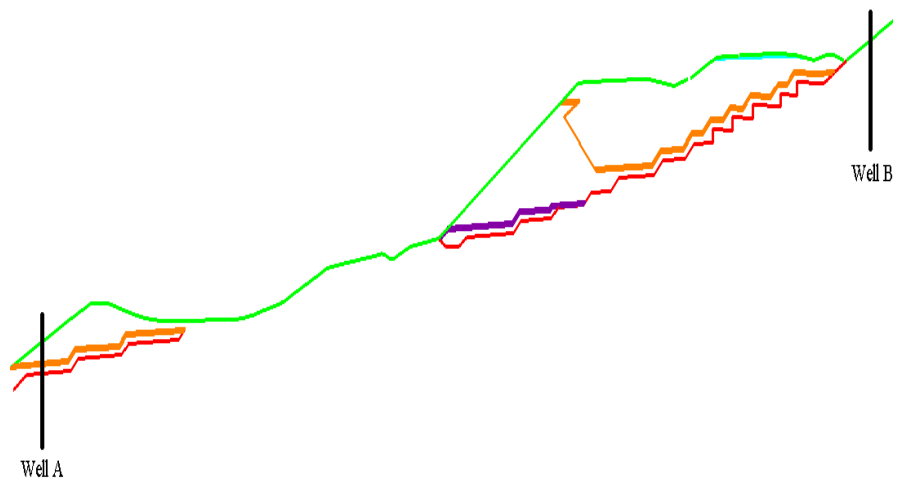

Figure 3: Location of monitoring wells upstream and downstream of highway.

Hydrologic elements are used to represent each of the sub-watersheds, the channels and the ponds. Runoff contributions are routed through these hydrologic components until they reach the watershed outlet where a Venturi flume is installed to continuously monitor the outflow. The characteristics of these elements and routing characteristics were determined from the construction drawings. Measurements were made to determine the water level changes at the storage ponds located within the test watersheds. This required the installation of water stage recorders to track the time variation of pond water levels. A Parshall 
Venturi flume was installed at the outlet of each watershed to measure runoff. Each of the flumes is provided with an automatic water level recorder which measures the depth of water at the throat of the Venturi flume. For tracking groundwater, deep monitoring wells were installed upstream and downstream of the roadway in each of the test watersheds in order to measure the fluctuations in groundwater levels. This is shown in Figure 3. Rainfall data were obtained from the precipitation gage nearby. Runoff data are transcribed from downloaded readout from water level recorders. Water levels are converted to discharge using the discharge rating curve provided by the manufacturer.

\section{Analysis}

The hydrograph prediction algorithm takes the precipitation input record, and runs it through the model in order to calculate the resulting runoff. The model takes into account abstractions that may be attributed to losses due to infiltration, soil moisture accretion, depression storage, basin recharge and evapotranspiration. For short-term events evapotranspiration losses are negligible. After correcting for base flow, the direct runoff is first checked if it equals the estimated rainfall excess to meet mass-balance requirements. The numerical criteria for model acceptability are that the calculated peak flow and the time to peak must not differ from the measured values by a significant amount. As a rule, a difference of $15 \%$ or less was deemed acceptable.

To explain the process, this report will discuss the data analysis and calibration procedure for the test watershed 1, identified in Figure 1. Because the watershed area is small (46.1 acres), it was assumed that the storm deposited a uniform depth on the whole watershed over its duration. As shown in Figure 2, the watershed was subdivided into seven sub-watersheds so that runoff contributions can be more accurately delineated. For each of the seven subwatersheds, the rainfall excess was calculated using the Soil Conservation Services method of relating the water retention characteristics to the nature of the surface, soil type and land use. For impervious surfaces such as the highway pavement, curve numbers in the range of 80-98 would be appropriate since most of the precipitation on impervious surfaces will be converted to runoff. Subtracting the abstraction from the precipitation resulted in excess rainfall amounts at each sub-watershed. These are then processed by routing them through the model components until the final outlet hydrograph is obtained. Processing included routing the runoff from dirty areas to two storm detention basins which also serve as sedimentation ponds.

In addition to a visual comparison, the numerical criteria for goodness-of-fit consisted of comparing the times to peak and the peak discharge as calculated by the model with the measured quantities. A difference of $15 \%$ was adopted as acceptable. After the model was calibrated, it was applied to several more storms.

Based on the results of the tests, we determined that the computer code for the hydrologic model that was developed to predict runoff has performed well. 
Hydrograph predictions for the significant storms that occurred during the testing period compared reasonably well with actual measurements.

\section{Effectiveness of the infiltration gallery}

The infiltration gallery is a new feature in the design. In this scheme, "dirty water" infiltrating from disturbed area would pass through an infiltration zone and be laterally transported downstream without mixing with "clean groundwater" coming from undisturbed areas upstream of the highway. The schematic of this is shown in Figure 4.

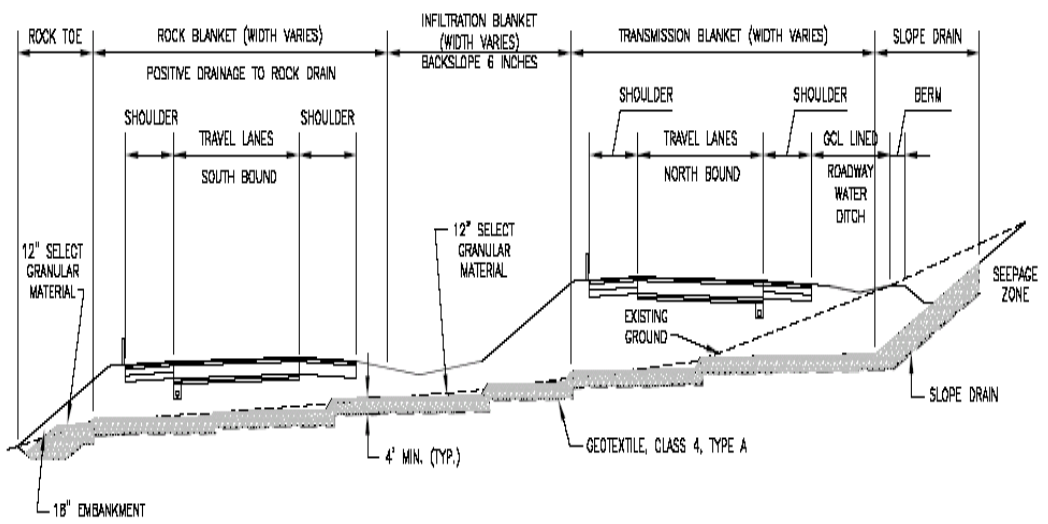

Figure 4: $\quad$ Schematic of infiltration gallery.

The infiltration gallery was intended to catch infiltrated dirty water (water from the disturbed portion of the watershed) and transport it laterally thus preventing it from percolating into the deep groundwater zone. The infiltration gallery, being constructed of fill material, represents a stratum of lower hydraulic conductivity than the natural subsurface zone. According to groundwater theory, the horizontal permeability of layered media is always greater than its vertical conductivity. Hence, in addition to the filtering effect, the gallery will indeed transport infiltrated dirty water laterally downstream where it will be captured in the storage pond. It is possible that some of this dirty water could percolate deeper and mix with the clean groundwater from above the highway. One method to examine the effectiveness of the infiltration gallery is to compare the quality of water in the pond with that of the water in the deep well downstream.

This comparison was carried out by sampling water from the ponds and the deep monitoring well nearby. The samples were analyzed to determine the concentrations of several minerals and pollutants at both locations. The water quality in the deep well which would represent deep groundwater flow is significantly better than the water quality of water in the pond which represents filtered dirty water. It was determined that the $\mathrm{pH}$ in the deep well is not significantly different from in the pond. As expected the conductivity in the pond 
was found to be almost twice as that in the well. Concentrations of iron and manganese between the ponds and the well are comparable. Those of magnesium and calcium are significantly higher in the ponds than in the well.

Table 1: $\quad$ Comparison of water quality in ponds and well.

\begin{tabular}{|c|c|c|c|c|c|c|}
\hline & $\mathrm{pH}$ & $\begin{array}{c}\text { Cond. } \\
(\mathrm{mg} / \mathrm{l})\end{array}$ & $\begin{array}{c}\mathrm{Mg} \\
(\mathrm{mg} / \mathrm{l})\end{array}$ & $\begin{array}{c}\mathrm{Ca} \\
(\mathrm{mg} / \mathrm{l})\end{array}$ & $\begin{array}{c}\mathrm{Mn} \\
(\mathrm{mg} / \mathrm{l})\end{array}$ & $\begin{array}{c}\text { Iron } \\
(\mathrm{mg} / \mathrm{l})\end{array}$ \\
\hline Pond 10 & 6.7 & 503 & 24 & 69 & 0.06 & 0.03 \\
\hline Pond 11 & 6.0 & 715 & 29 & 110 & 0.08 & 0.03 \\
\hline Well B & 6.0 & 314 & 15 & 47 & 0.07 & 0.03 \\
\hline
\end{tabular}

In order to carry out the verification of effectiveness, a monitoring program which documents the above practices as construction proceeds was set up. This includes periodic visits to the sites of BMPs and recording changes in erosion prevention structures due to construction traffic, vegetation growth and extraordinary runoff episodes, documenting them with photographs for later analysis to determine their effectiveness recording effectiveness.

\section{Instrumentation}

Modeling support for impact assessment requires not only a site-specific formulation of the hydrologic interactions. It also requires instrumenting the watershed to verify the model performance. At a minimum, one must provide for the installation and maintenance of equipment used for observing variables at various points of the watershed. For the test watersheds, deep monitoring wells and shallow groundwater stage recorders are required. Storage ponds must be equipped with stage recorders to track storage fluctuations. Flow recorders at the watershed outlet and precipitation and other hydro-meteorological variable must be tracked.

All measurement gages must be capable of continuously recording and storing data. This enables downloading information at regular intervals and reduces the frequency of field visits. All the instruments used in this study were equipped with automatic recorders. Data downloads were made approximately every month.

The flow metering device needed at the watershed outlet depends on the size of the watershed. The device should cover the range of discharges that can be expected. For small watersheds, as in the present case, a Parshall flume was selected. This must be provided with a metering device that can continuously record the discharge to capture the hydrograph from a storm.

For monitoring the deep groundwater zone, at least two wells must be installed - one to capture the groundwater levels above and another below the impacted area. Shallow groundwater may be tracked using commercially 
available water stage recorders. Water level fluctuation in storage ponds must be tracked to carry out hydrograph routing.

It is critical that precipitation data for calibrating and testing the model be accurate and reliable. The possibility of record interruption due of a power cut off should also be anticipated. A back-up power system is recommended.

For impact analysis, it is required to compare conditions before and after construction. This implies that monitoring must commence before actual construction begins. Monitoring instruments must therefore be installed as soon as the highway alignment has been determined and test watersheds can be delineated. Finally, periodic checks must be made to determine if instruments are functioning as intended

\section{Conclusions}

In order to complete an Environmental Impact Analysis for a construction project, one must have a hydrologic model to obtain numerical measures of water quantity and quality. The development of a model to predict runoff is therefore an indispensable requirement. In formulating the model one must take into account the altered watershed delineation and instrument the watershed to capture changes in the environment engendered by the construction project. In addition to the mathematical development, the field verification of the hydrological model requires installation of data acquisition hardware supported by software that permits continuous monitoring of the variables. These must be installed as early as possible in order to capture changes in hydrologic quantities as a result of the project.

\section{Acknowledgements}

This research was supported by the Pennsylvania Department of Transportation. The author would like to thank Tom McNally, Mike Bonini, Kevin Kline and many others at PennDOT who have helped in the conduct of this research and assisted in resolving logistical problems during the study.

\section{References}

[1] Bruntland, G. (ed.), Our common future: The World Commission on Environment and Development, Oxford, Oxford University Press, 1987.

[2] Carson, R., Silent Spring, Houghton Mifflin, New York, 1962

[3] Meadows, D. et al., Limits to Growth, Universe Books, New York, 1972. 